\title{
A NEW POISONOUS MUSHROOM
}

(WITH THREE FIGURES)

The genus Clitocybe is a large one, with approximately 400 species. Very few of this large number are known to be poisonous or deleterious in other ways when eaten. Among these may be mentioned from North

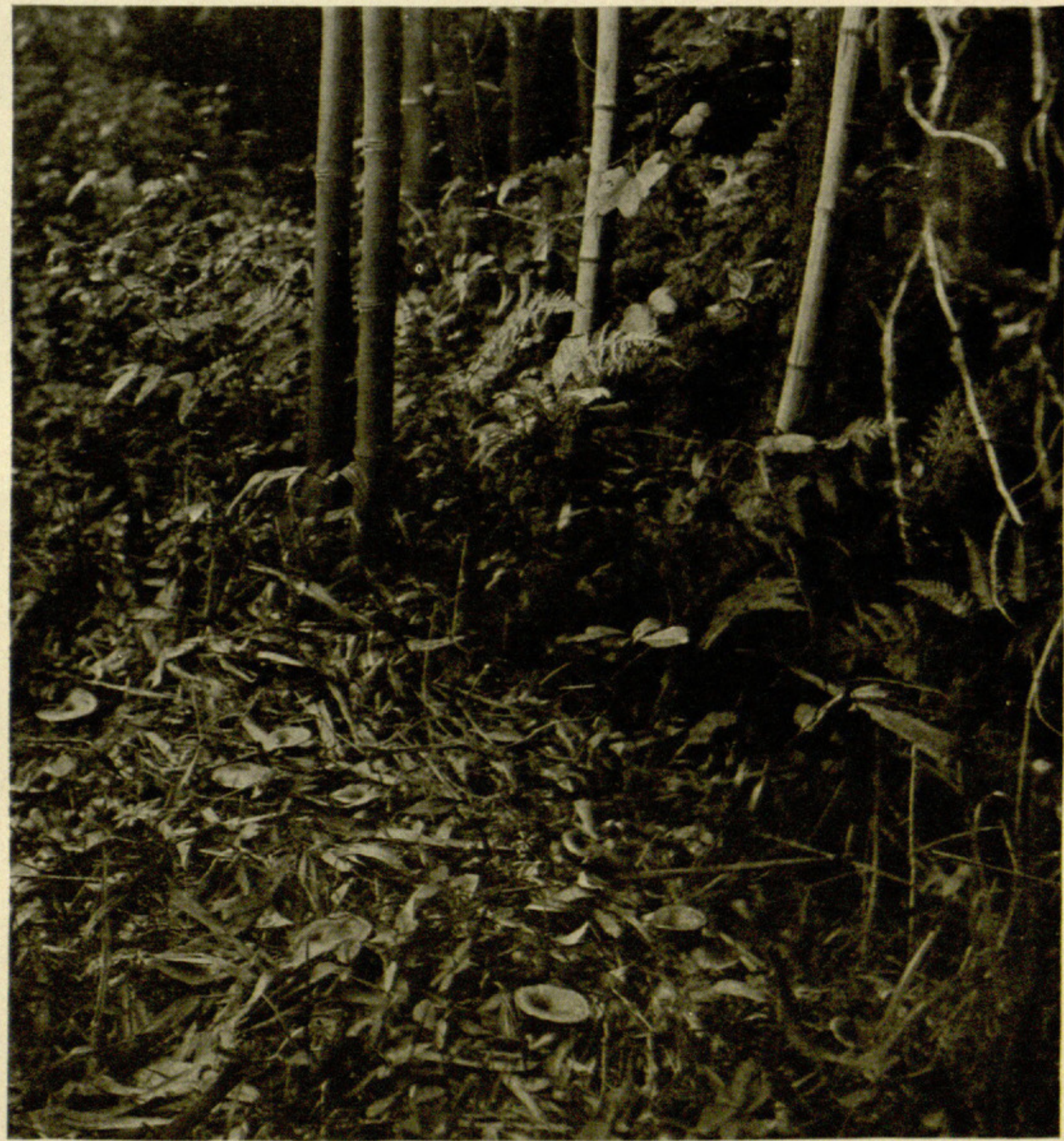

Fig. I. - C. acromelalga growing on ground in bamboo forest

America the phosphorescent species $C$. illudens Schw., which produces serious nausea, and $C$. sudorifica $\mathrm{Pk}$., which, eaten in small quantities, causes a "profuse perspiration sometimes continuing for 5 or 6 hours" (N.Y. State Mus. Bull. no. I57. 68. I9I2), but is "sufficiently toxic to cause the death of frogs, rabbits, and guinea pigs." It is a matter of 
interest, therefore, to record the discovery of another poisonous species of this genus, which is also a hitherto undescribed one. It was

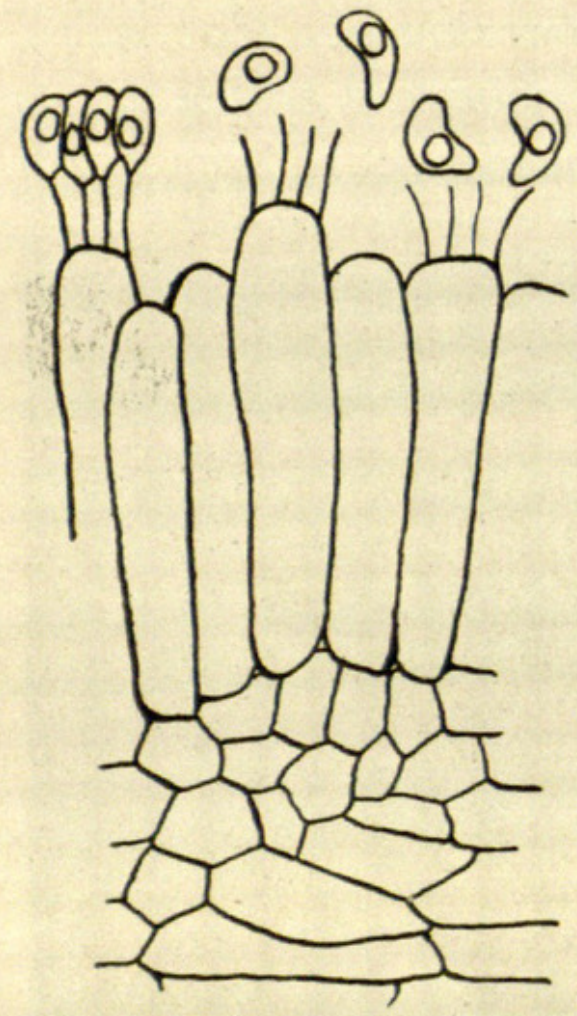

FIG. 2,-Basidiospores of C. acromelalga; $\mathrm{X}_{5} 500$. found growing on the ground among other vegetation in a bamboo forest in Tsurugiji, Noto, Japan. The poisonous effects from eating this mushroom are manifested by an acute burning pain in the fingers and toes within 3 days. The pain is mitigated by placing the hands and feet in running water.

Clitocybe acromelalga, n. sp.-Plants $3^{-6} \mathrm{~cm}$. high; pileus $5^{-10} \mathrm{~cm}$. broad, orange yellow when fresh, dark brown red when dry, subfleshy and pliant, depressed, margin incurved when young, splitting in age, surface smooth, flesh white; lamellae white, crowded, thin, slightly decurrent; basidia 4-spored; spores white, smooth, oboval, $3^{-4} \times 1 \cdot 5^{-2} \cdot 5 \mu$; stem rigid, fibrous, hollow, concolorous with the pileus, $2-5 \mathrm{~cm}$. long, $0.5^{-1} \mathrm{~cm}$. thick.Odor and taste not marked, Poisonous effects, acromelalga. October to November, on the ground in a bamboo forest, Tsurugiji, Noto, Japan.-T. Ichimura, Kanazawa, Japan. 


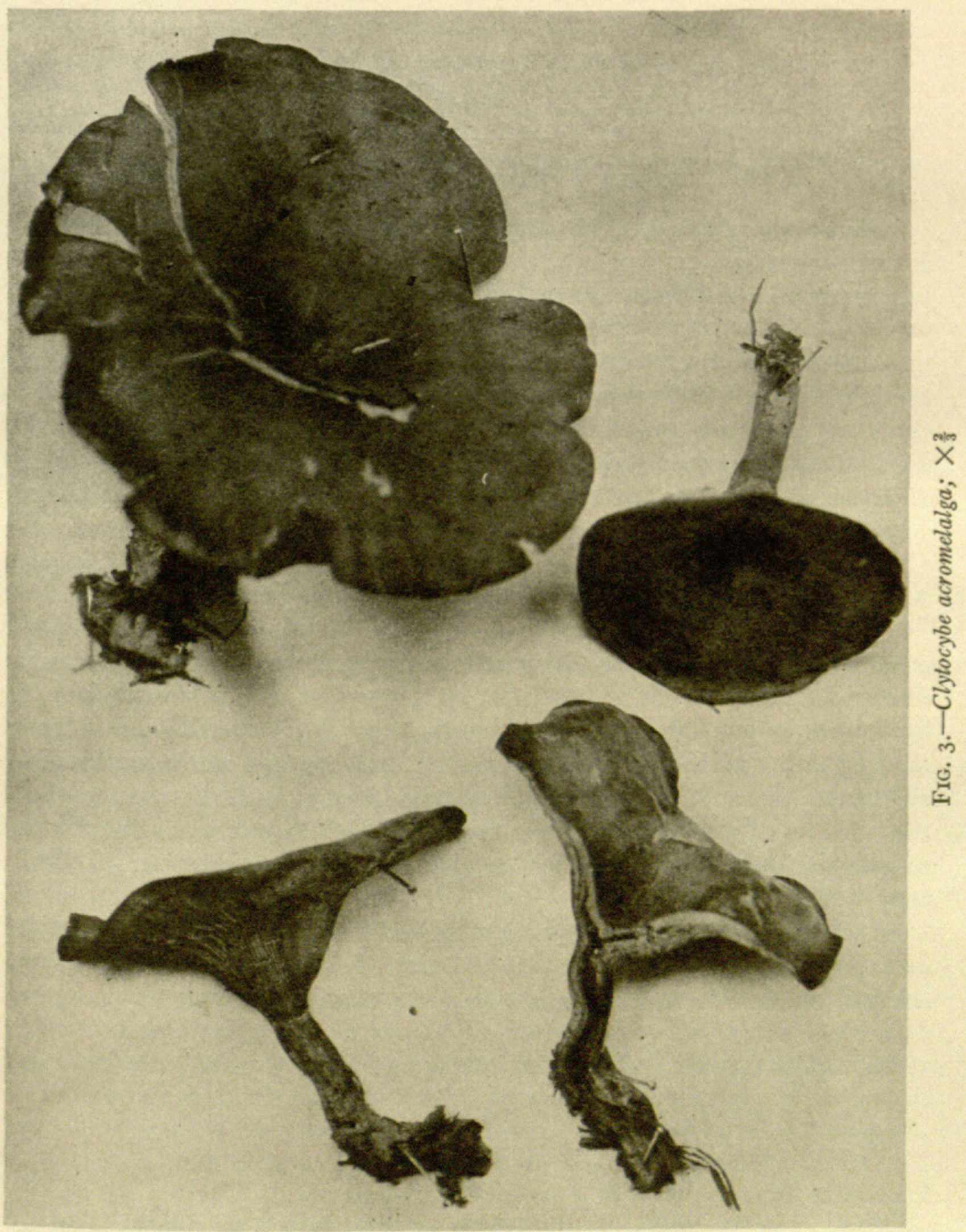




\section{$2 \mathrm{BHL}$ Biodiversity Heritage Library}

Ichimura, T . 1918. "A New Poisonous Mushroom." Botanical gazette 65(1), 109-111. https://doi.org/10.1086/332195.

View This Item Online: https://www.biodiversitylibrary.org/item/109339

DOI: https://doi.org/10.1086/332195

Permalink: https://www.biodiversitylibrary.org/partpdf/223968

\section{Holding Institution}

Missouri Botanical Garden, Peter H. Raven Library

\section{Sponsored by}

Missouri Botanical Garden

\section{Copyright \& Reuse}

Copyright Status: Public domain. The BHL considers that this work is no longer under copyright protection.

This document was created from content at the Biodiversity Heritage Library, the world's largest open access digital library for biodiversity literature and archives. Visit BHL at https://www.biodiversitylibrary.org. 